\title{
New Configurations of Power Converters for Grid Interconnection Systems
}

\author{
Marco Rivera, Member, IEEE, Sergio Toledo, Member, IEEE, Usman Nasir, Member, IEEE, \\ Alessandro Costabeber, Member, IEEE, and Patrick Wheeler, Member, IEEE
}

\begin{abstract}
The increased penetration of renewable energy sources and other distributed energy sources has been seen nowadays. In this scenario power converters play a crucial role by providing the interconnection of these energy sources. This paper presents new configurations of power converters for grid interconnection systems. Several topologies are analyzed which are based on isolated ac-ac matrix converters.
\end{abstract}

Index Terms-Grid interconnection, Power converters, Galvanic Isolation

\section{INTRODUCTION}

According to the Energy Program 2014-2018 from the Chilean Minister of Energy ${ }^{1}$, the technological and economical development of the country has lead to an increase in the energy demand in Chile. It is well known that energy resources based on fossil fuels are very limited in the country. Chile has little natural gas and oil resources and, at the same time, the extraction costs of coal are high. In addition, there is huge social opposition to the electrical development, because the perception of the community to this development is associated with environmental deterioration and social cost.

This has lead to higher generation costs and thus high electricity prices for the consumers. With all this what is needed is a "safe and efficient energy development, with reasonable prices, that take advantage of the renewable resources in a sustainable and non-polluting way".

In order to avoid the events experienced after the big earthquake and last huge storm in the north and central areas of the country (communication problems and thousands of people without electricity), recent initiatives from the government have been focused on electrical systems interconnection, to the promotion of using non-conventional renewable energies, and the installations of microgrids in isolated areas as well as the inclusion of redundancy and reliability of the interconnected system. In all of these initiatives, power converters play a critical role because they allow the integration to the electrical network of different kind of generation and distribution systems.

In the last years the concept of microgrids has become very popular. "A microgrid is a localized station with its own power

M. Rivera, and S. Toledo are with the Department of Electrical Engineering, Faculty of Engineering, Universidad de Talca, Curic, PB, 3341717 CHILE email: marcoriv@utalca.cl (see https://marcorivera.cl/).

U. Nasir, A. Costabeber and P. Wheeler are with the Department of Electrical Engineering, Faculty of Engineering, The University of Nottingham, Nottingham, UK e-mail: Alessandro.Costabeber@nottingham.ac.uk.

Manuscript received July 13, 2016; revised XXX XX, 2016.

${ }^{1}$ http://www.minenergia.cl resources, generation and loads, which is intended as a backup power or to bolster the main power grid during periods of heavy demand. Often, microgrids involve multiple energy sources as a way of incorporating renewable energy. Other purposes include reducing costs and enhancing reliability." [1]. In the last years it is possible to find different microgrid systems based on alternative renewable energies such as: solar (photovoltaic - thermal) [2]-[6], wind [7]-[12], ocean [12], micro-hydro [6], [10], [13], geothermal [14], [15], among others. Most of these microgrid clusters are working in islanded or grid interconnected modes.

In this context, power converters are critical, because they allow the integration to the electrical network with different kinds of generation and distribution systems. The most traditional power converters used in these applications are active front end rectifiers (AFE) [16], [17], two-level voltage source converters (2L-VSI) [18]-[20] and multilevel power converters such as the three-level neutral point clamped (3L-NPC) converters [21]-[23] and cascade H-Bridge topologies [24]. Modular multilevel converter technologies have emerged also as a suitable solution to the integration of renewable energy to the electrical grid [25]-[27]. As it can be reviewed, most of the power converters commonly used nowadays include storage elements which introduce size, weight and failure possibilities in the system.

An alternative to the converters with storage elements is the matrix converter (MC) which is shown in Fig. 1. The MC is a simple and compact power circuit that directly connects the AC-source with any arbitrary AC-load without the need for large storage elements, making this topology suitable for many applications where weight and size are important issues [28]-[30].

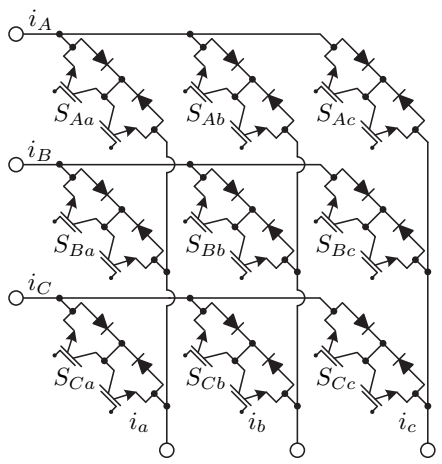

Fig. 1. Power topology of the conventional direct matrix converter. 
With MC topologies the generation of output voltages of any different amplitude and frequency, sinusoidal input and output current waveforms, as well as operation with unity displacement power factor and regenerative capability are all possible. One of the challenges of MCs used to be the commutation of current between the bidirectional switches, but this issue has been solved with multi-step commutation techniques [31]. Due to these characteristics, in recent years MCs have shown continuous and fast development related to the development of new topologies and control methods, including industrial applications with standard units for high and medium voltage using cascade connections [32], [33].

The main goal of this paper is to contribute to the energy development of the country by proposing and studying new configuration of power converters based on multiport modular power converter structures.

\section{The UsE OF MATRIX CONVERTERS FOR GRID INTERCONNECTION SYSTEMS}

Different modulation and control methods for MCs can be found in the literature [34]-[37]. These methods have different implementations and different levels of complexity, but all have dynamic behavior which is acceptable in a variety of applications. As reviewed in [38], the most used techniques are Venturini, carrier-based pulse width modulation (PWM), space vector modulation (SVM) and direct torque control (DTC) [38]-[43]. Other methods that have been applied to MCs in specific applications are fuzzy control, neural networks and genetic algorithms [44]-[46]. Predictive control has shown to be a very interesting alternative for control MCs because the use of the discrete nature of power converters and its simplicity for implementation and intuitive approach [36], [37], [47].

Matrix converters have emerged as a flexible and efficient alternative to manage energy in specific applications such as military, aerospace, wind generation systems among others. However, they have not been deeply studied in applications for grid interconnection of microgrids, generation systems and/or loads. The work done in [48] has considered a modified matrix converter topology for grid integration of two AC sources to the utility, demonstrating that "this converter is very suitable to integrate two AC type power sources into the utility grid" [49], [50].

In order to use the matrix converter in high power applications, new multilevel topologies have appear in the last years. These new configurations allow "high power quality, high-voltage capability, low switching losses and low EMI issues" [51]. In [52], a multimodular matrix converter for wind power generation applications is proposed. The same idea has been presented in [33] and [53] for other applications such as blowers, pumps, extruders, mixers, kilns, etc., where the basic block of the modular matrix converter is a threeinput one-output module with six bidirectional switches. This structure allows the use of low voltage power semiconductors, with low switching frequency and also the generation of high-quality output waveforms. The common modulation and control strategies developed for these topologies are PWM and SVM techniques.

\section{Power Converter Topologies With MF/HF}

ISOLATION FOR GRID INTERCONNECTION SYSTEMS

It is well known that the most of the present Chilean architecture network is only in one direction: the electricity is generated from the power stations and transmitted to the users through high voltage transmission systems. Recent initiatives of the Chilean government and recent research have focussed on "providing a more flexible and modular power electronics interface able to connect different kind of sources and loads including medium voltage electrical networks, renewable energy sources, and energy storage systems", such as the one illustrated in Fig. 2 which requires a flexible power management control in order "to ensure proper and secure operation of the networks" and bidirectional power flow [54].

Some requirements for the future electricity network are:

- Galvanic Isolation.

- Multi-directional power flow capability.

- Flexibility and scalability.

- Easy maintenance and low cost.

- Compact power conversion and low weight.

- High efficiency and reliability.

The general structure for grid interconnection shown in Fig. 2 can be formed by two different configurations:

1) Two AC/DC stages and a DC/DC stage with isolation medium or high frequency $(\mathrm{MF} / \mathrm{HF})$ transformers. In this case single phase H-bridge converters are used (Fig. 3).

2) Two $\mathrm{AC} / \mathrm{AC}$ stages with isolation $\mathrm{MF} / \mathrm{HF}$ transformers. In this case single phase matrix converters are used (Fig. 4).

Both configurations use the advantages of multimodular structures based on single phase power converters (shown in Fig. 5) in a cascade connection to provide a more flexible and modular power electronic interface to connect different types of microgrids and generation systems including medium voltage electrical networks, renewable energy sources and energy storage systems. Some characteristics of both architectures are:

- Both configurations are modular structures, allowing easy replacement of the cells in case of failure.

- Both configurations have the same number of semiconductor devices. In each cell of the first architecture there are four H-bridges, which implies 16 semiconductor devices. In the second configuration, there are two single phase matrix converters, which have also 16 semiconductor devices.

- Both configuration schemes are able to operate with multi-directional power flow.

- Different from the first configuration structure, the second alternative topology does not include energy storage elements, reducing the weight and size.

- Because the second configuration architecture does not include energy storage elements, there is no need for DClink controllers and the potential for failure is reduced.

Recent investigations have been focused in to propose microgrid clusters and generation systems based on different power converter configurations when used for nonconventional renewable energies. Such configurations must ensure an optimal active and reactive power flow control 


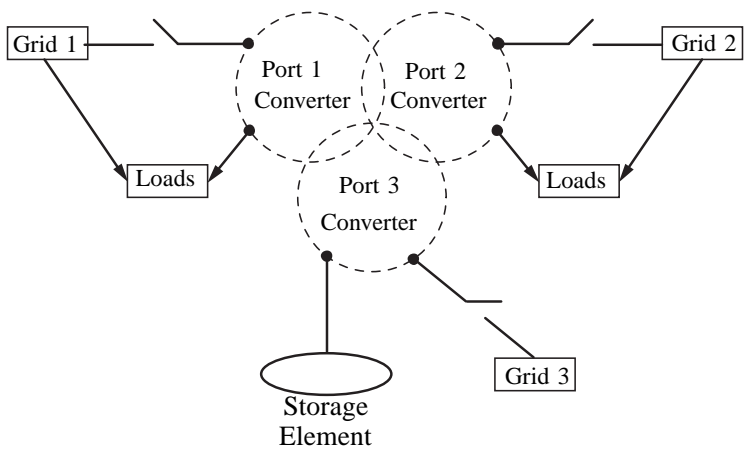

Fig. 2. General structure of the universal and flexible model for grid interconnection.

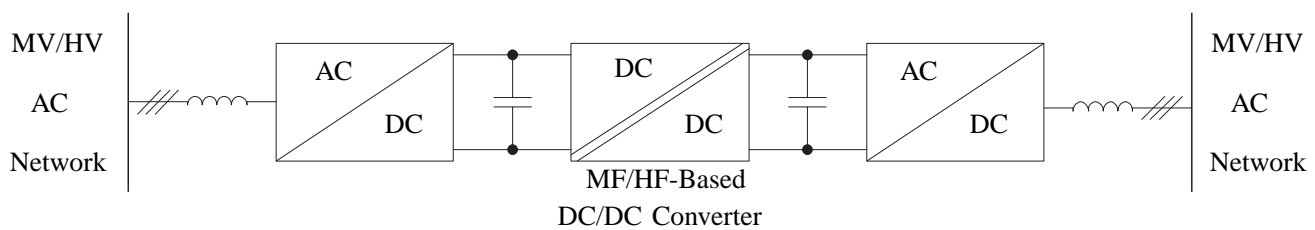

Fig. 3. Basic schematic block of the first configuration: two AC/DC stages and a DC/DC stages with isolation MF/HF transformers based on H-bridge converters.

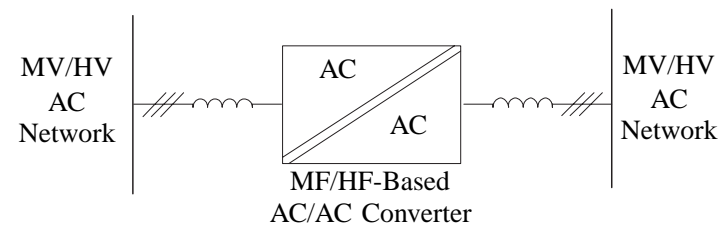

Fig. 4. Basic schematic block of the second configuration: two AC/AC stages with isolation MF/HF transformers based on single phase matrix converters.

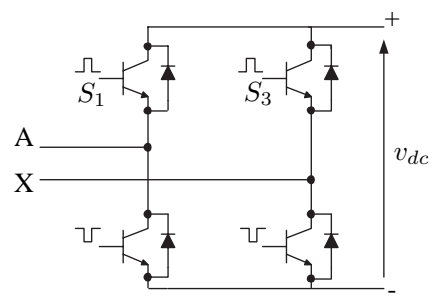

a)

Fig. 5. Basic topologies: a) H-bridge; b) single phase matrix converter.

and flexibility to be adapted to different load/users/grid conditions such as parameter variations, load changes, voltage imbalances, harmonic content, resonances and others. In order to achieve all these requirements, different modulation and control strategies have been proposed in the literature. Among them, pulse width modulation (PWM), space vector modulation (SVM), fuzzy control, predictive control and others, are currently the most popular [55], [56]. But, despite the several advances in new technologies and control strategies for microgrids and generation systems when working in standalone mode or grid interconnected, there is still need for novel improvements to make them more reliable, smart, cooperative and an open system to the inclusion of new generation systems.

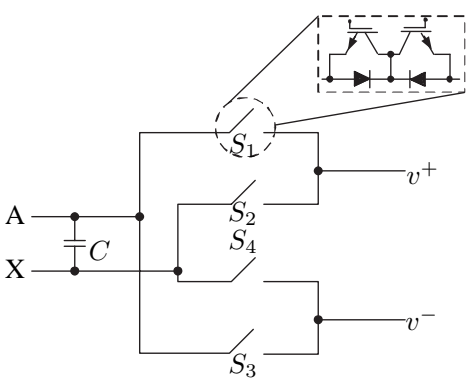

b)

\section{A. Modulation of single phase AC/MF/AC}

A Dual-CBM configuration for $\mathrm{AC} / \mathrm{MF} / \mathrm{AC}$ solution is shown in Fig. 7. In Dual-CBM, a low frequency input voltage is modulated to a medium/high frequency voltage waveform and then it is demodulated to low frequency output voltage as shown in Fig. 8. The shown solution works well when demanded frequency is equal to input frequency i.e. fi=fo and is a good alternative in this case for grid interconnection applications. Due to the single phase nature of the solution, output voltage frequency is limited to only integral multiples of the input voltage frequency. For instance, with an input voltage at $60 \mathrm{~Hz}$, it is only possible to generate $30 \mathrm{~Hz}, 20 \mathrm{~Hz}$, $15 \mathrm{~Hz}$ and so on. This constraint can be formulated as: 


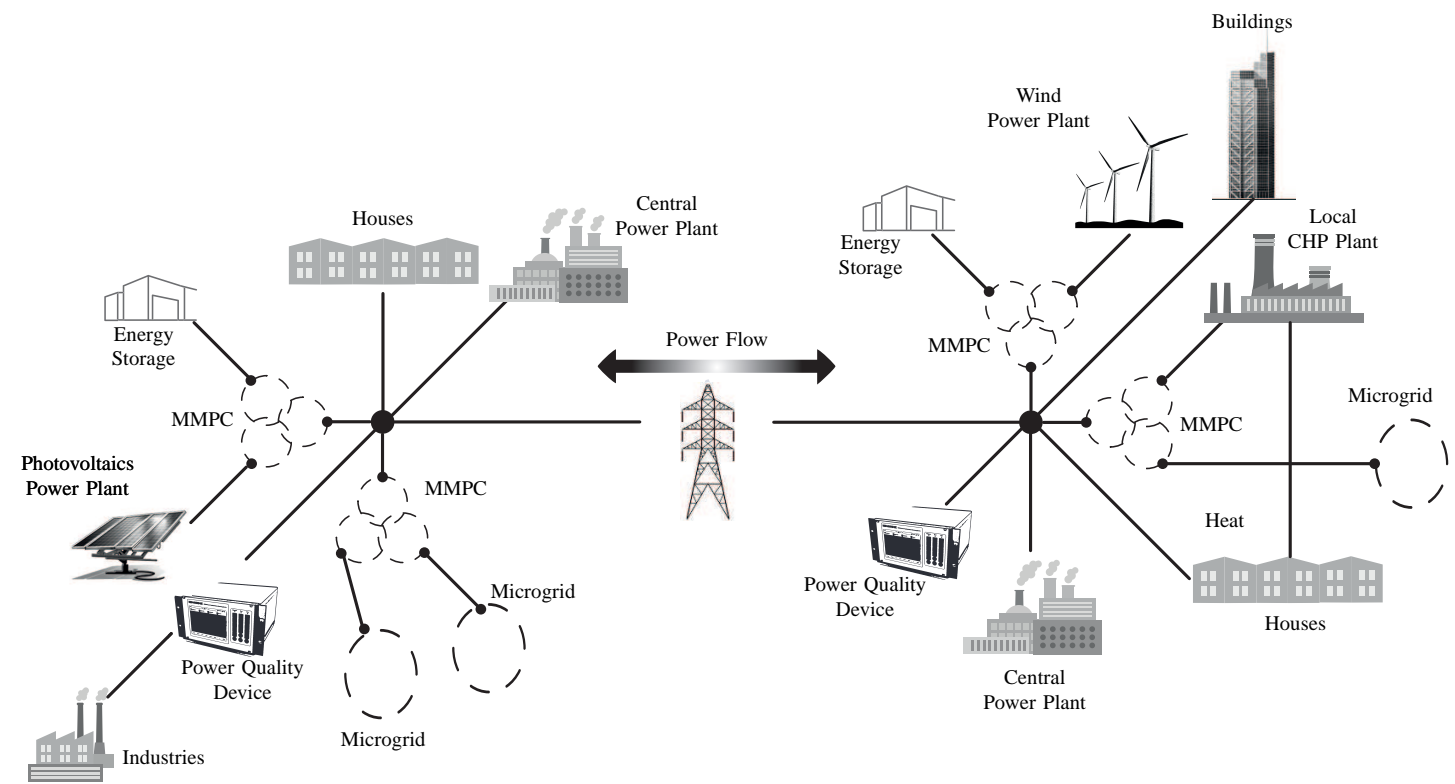

Fig. 6. Microgrid clusters and generation systems based on multiport modular power converter (MMPC) structures with fully integrated network management.

$$
f_{o}=\frac{f_{i}}{n}, \quad \forall n \in Z^{+}, \quad Z^{+}=1,2,3 \ldots
$$

Some countries are utilizing $60 \mathrm{~Hz}$ while others are utilizing $50 \mathrm{~Hz}$ as grid frequency and the interconnection of said grids via Dual-CBM is not feasible as 50 is not an integral multiple of 60 , therefore violating the constraint. This can be validated Fig. 9, when $50 \mathrm{~Hz}$ output is generated from a $60 \mathrm{~Hz}$ input. Furthermore, it is important for the converter in MMPC to be fully able to generate any frequency at the output.

\section{B. New AC/MF/AC topology for grid interconnection systems}

Now, it is clear that the single phase solution has some drawbacks as:

- Its failure in the applications interconnecting two systems at different frequencies e.g. interconnection of $60 \mathrm{~Hz}$ and $50 \mathrm{~Hz}$ grid.
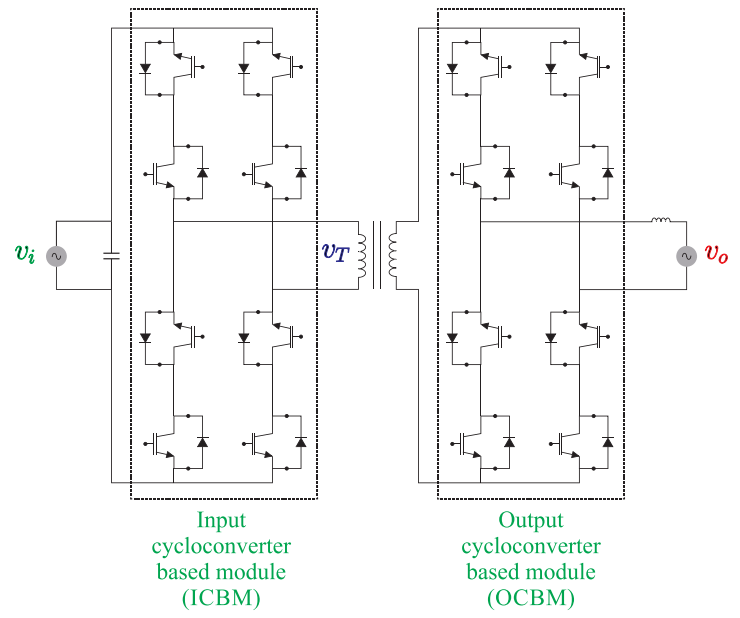

Fig. 7. Dual-CBM configuration

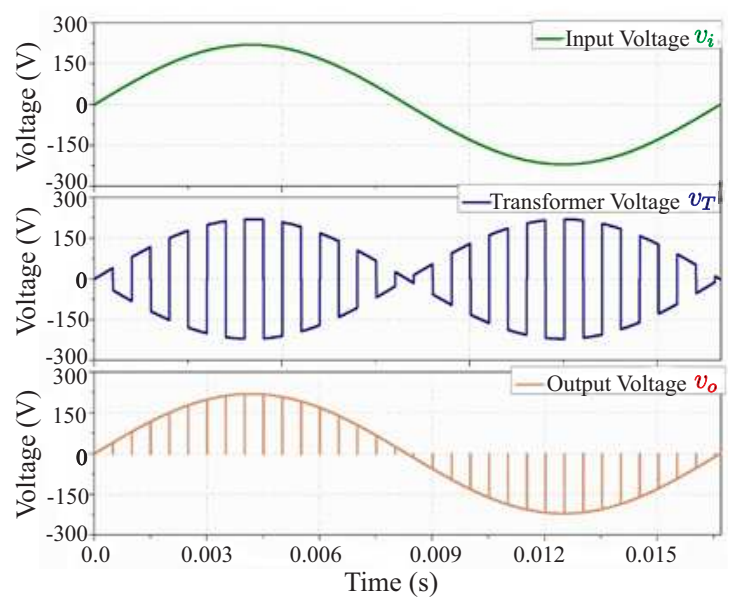

Fig. 8. Voltages in the dual CBM

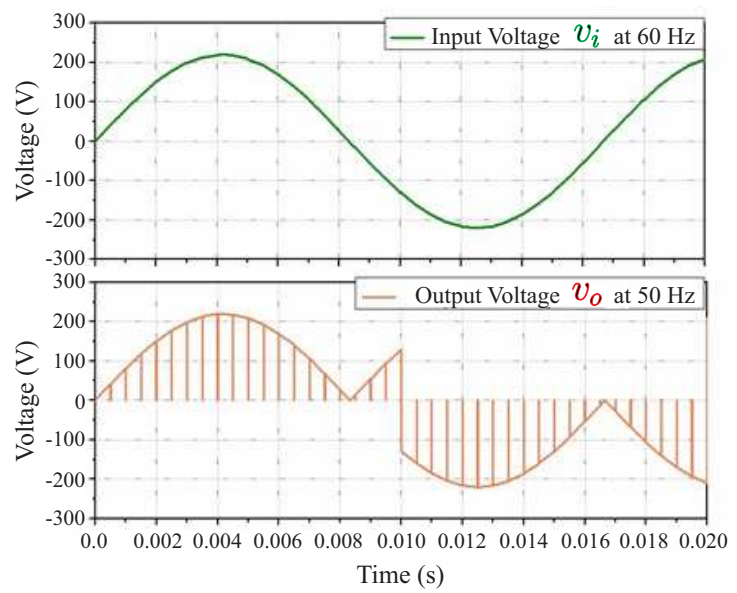

Fig. 9. Voltages in the dual CBM when $f_{o}<f_{i}$ 


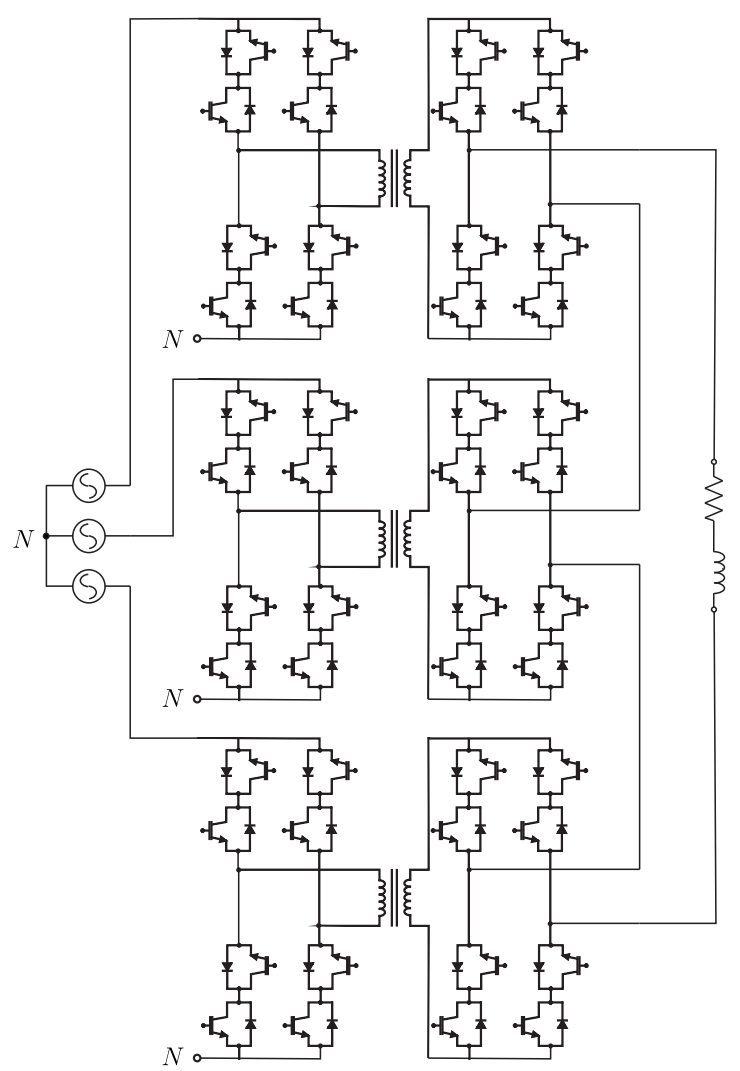

Fig. 10. A new 3-phase to 1-phase isolated AC/AC topology using three Dual CBMs

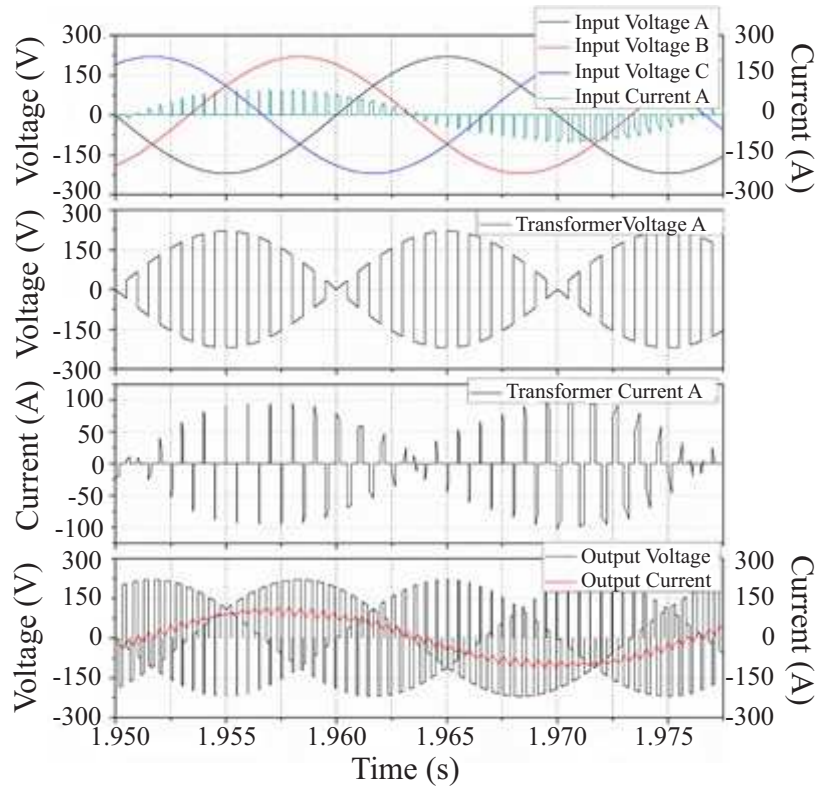

Fig. 11. Systems behavior for an input of $50 \mathrm{~Hz}$ and a output of $40 \mathrm{~Hz}$

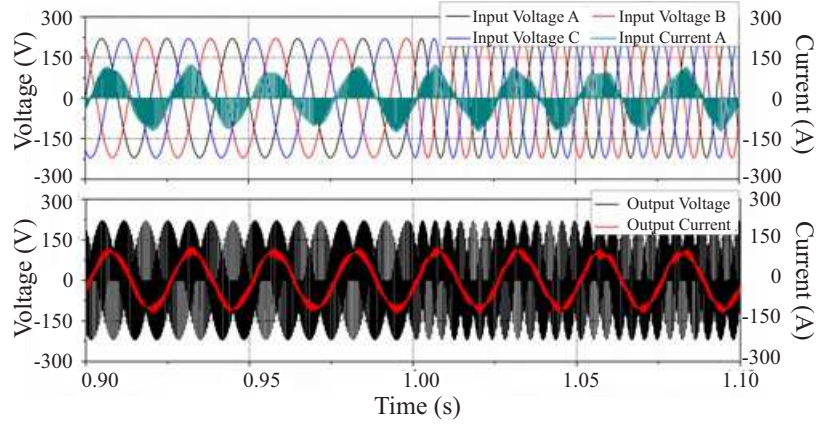

Fig. 12. Systems behavior for a changing input

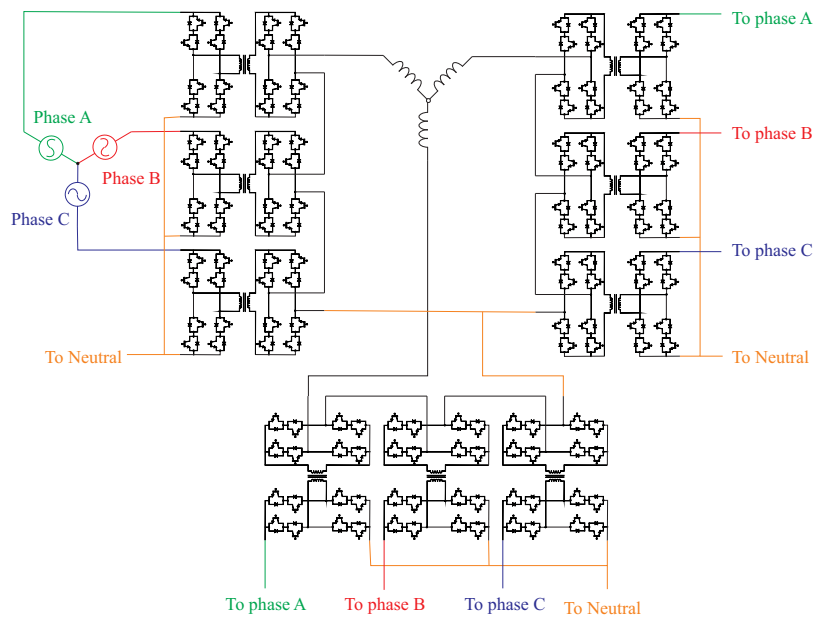

Fig. 13. A new 3-phase to 3-phase isolated AC/AC topology

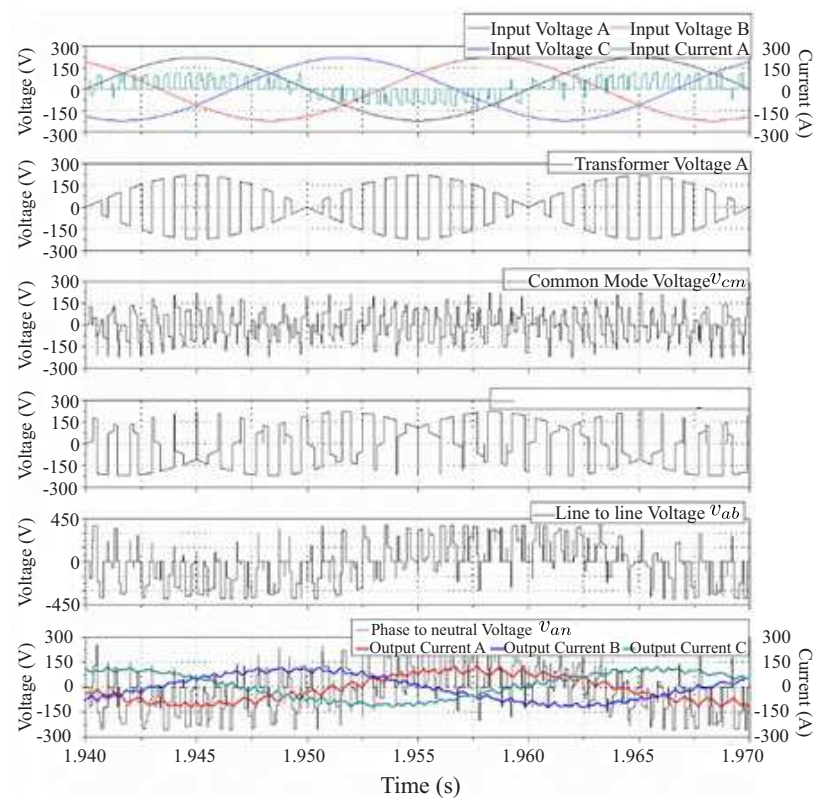

Fig. 14. Voltages and currents in the three-phase to three-phases interconnection proposal. 
- It is not a viable solution for the applications requiring frequency regulation e.g. v/f control of drives.

The reasons of mentioned drawbacks are that converter has single phase input i.e. output is limited to single phase input in terms of selection. A possible solution for this limitation consist of increasing the input options of the converter i.e. utilizing the concept of matrix converters. The topology can be modified to Fig. 10 therefore, utilizing three-phase input in a way to have three input options at any time and at the same time also providing modularity, galvanic isolation, bidirectional power capability etc. With the new topology of Fig. 10 , it is possible to generate, at the output, the non-integral multiples of the input i.e. $40 \mathrm{~Hz}$ output voltage is generated from $50 \mathrm{~Hz}$ input voltage as shown in Fig. 11. Not only that but the new topology also provides excellent output grid frequency regulation even when validated with an exaggerated variation in input grid frequency i.e. $50 \mathrm{~Hz}$ to $86 \mathrm{~Hz}$ at $\mathrm{t}=1 \mathrm{~s}$ as shown in Fig. 12. Eventually, a three phase to single phase AC/AC isolated converter system can be extended to three phase to three phase system as shown in Fig. 13. It is important to mention that the input and output voltage and currents of the three phase to three phase topology, shown in Fig. 14, are similar to that of classical matrix converters. This new converter topology can be a step forward, considering the utilizing of bi-directional switch based converters, in the grid interconnection applications.

\section{CONCLUSIONS}

The growing technological development has increased the demand of more available energy. It is necessary a safe and efficient energy development, with reasonable prices, that take advantage of the renewable resources in a sustainable and nonpolluting way. There are several power converter topologies for micro-grid applications.

Potential of isolated $\mathrm{AC} / \mathrm{AC}$ direct converter topologies has been discussed. Identification of problem in a single cell i.e. in a single phase to single phase topology. Modification of the topology comes at the cost of an increased number of switching devices while keeping modularity intact as well as bi-directional power flow. This new $\mathrm{AC} / \mathrm{AC}$ isolated topology will have a wider range of applications e.g. grid applications, AC drives etc.

\section{ACKNOWLEDGMENTS}

This publication was made possible by the FONDECYT Regular 1160690 and Newton Picarte Project EPSRC: EP/N004043/1: New Configurations of Power Converters for Grid Interconnection Systems / CONICYT DPI20140007.

\section{REFERENCIAS}

[1] L. I. Dulau. Economic analysis of a microgrid, Fundamentals of Electrical Engineering (ISFEE), 2014 International Symposium on, Bucharest, 2014, pp. 1-4. doi: 10.1109/ISFEE.2014.7050554

[2] Hongtao Shi; Fang Zhuo; Hao Yi; Feng Wang; Dong Zhang; Zhiqing Geng, A Novel Real-Time Voltage and Frequency Compensation Strategy for Photovoltaic-Based Microgrid, Industrial Electronics, IEEE Transactions on , vol.62, no.6, pp.3545,3556, June 2015. doi: 10.1109/TIE.2014.2371434.
[3] Patterson, M.; Macia, N.F.; Kannan, A.M., Hybrid Microgrid Model Based on Solar Photovoltaic Battery Fuel Cell System for Intermittent Load Applications, Energy Conversion, IEEE Transactions on , vol.30, no.1, pp.359,366, March 2015. doi: 10.1109/TEC.2014.2352554

[4] Elrayyah, A.; Sozer, Y.; Elbuluk, M., Microgrid-Connected PV-Based Sources: A Novel Autonomous Control Method for Maintaining Maximum Power, Industry Applications Magazine, IEEE , vol.21, no.2, pp.19,29, March-April 2015. doi: 10.1109/MIAS.2014.2345822

[5] Peng Li; Xiaomeng Yu; Jing Zhang; Ziheng Yin, The $H_{\infty}$ Control Method of Grid-Tied Photovoltaic Generation, Smart Grid, IEEE Transactions on , vol.6, no.4, pp.1670,1677, July 2015. doi: 10.1109/TSG.2015.2409371

[6] Guan, Y.; Vasquez, J.C.; Guerrero, J.M.; Wang, Y.; Feng, W., Frequency Stability of Hierarchically Controlled Hybrid PhotovoltaicBattery-Hydropower Microgrids, Industry Applications, IEEE Transactions on , vol.PP, no.99, pp.1,1. doi: 10.1109/TIA.2015.2458954.

[7] Kim, Jaewoo; Kim, Dongmin; Baek, Seung-Mook; Lee, Soo Hyoung; Park, Jung-Wook, A survey on operation of wind turbine generators in stand-alone microgrid, Power Electronics and ECCE Asia (ICPE-ECCE Asia), 2015 9th International Conference on , vol., no., pp.377,384, 1-5 June 2015. doi: 10.1109/ICPE.2015.7167814.

[8] Kai-Wei Hu; Chang-Ming Liaw, Development of a Wind Interior Permanent-Magnet Synchronous Generator-Based Microgrid and Its Operation Control, Power Electronics, IEEE Transactions on , vol.30, no.9, pp.4973,4985, Sept. 2015. doi: 10.1109/TPEL.2014.2360563.

[9] Alalwan, S.H.; Kimball, J.W., Optimal Sizing of a Wind/Solar/Battery Hybrid Microgrid System Using the Forever Power Method, Green Technologies Conference (GreenTech), 2015 Seventh Annual IEEE, vol., no., pp.29,35, 15-17 April 2015. doi: 10.1109/GREENTECH.2015.21.

[10] Bhim Singh; Bhalla, K.K., Reduced converter topology for integrated wind and small-hydro energy generation system, Renewable Power Generation, IET , vol.9, no.5, pp.520,529, 72015. doi: 10.1049/iet-rpg.2014.0235.

[11] Hossain, M.J.; Pota, H.R.; Mahmud, M.A.; Aldeen, M., Robust Control for Power Sharing in Microgrids With Low-Inertia Wind and PV Generators, Sustainable Energy, IEEE Transactions on , vol.6, no.3, pp.1067,1077, July 2015. doi: 10.1109/TSTE.2014.2317801.

[12] Sheng-yen Lu; Li Wang; Te-Ming Lo; Prokhorov, A.V., Integration of Wind Power and Wave Power Generation Systems Using a DC Microgrid, Industry Applications, IEEE Transactions on , vol.51, no.4, pp.2753,2761, July-Aug. 2015. doi: 10.1109/TIA.2014.2367102.

[13] Dinushi, H.M.N.; Kariapper, M.H.M.S.; Porawagamage, G.D.; Rathnayaka, P.K.H.; Srimal, U.P.; Hemapala, K.T.M.U., Defining multi agent system for a reliable micro-grid, Moratuwa Engineering Research Conference (MERCon), 2015 , vol., no., pp.94,99, 7-8 April 2015 doi: 10.1109/MERCon.2015.7112327.

[14] Setel, A.; Gordan, M.; Antal, C.; Bococi, D., Use of geothermal energy to produce electricity at average temperatures, Engineering of Modern Electric Systems (EMES), 2015 13th International Conference on , vol., no., pp.1,4, 11-12 June 2015. doi: 10.1109/EMES.2015.7158398.

[15] Mayer, M.J.; Nyerges, V.; Schroth, A., Investigation of geothermal power generation on abandoned hydrocarbon wells, Energy (IYCE), 2015 5th International Youth Conference on , vol., no., pp.1,7, 27-30 May 2015. doi: 10.1109/IYCE.2015.7180820.

[16] Chung-Chuan Hou; Yung-Fu Huang, Diode Rectifier With Auxiliary Converter for Hybrid AC/DC Microgrids, Emerging and Selected Topics in Power Electronics, IEEE Journal of , vol.2, no.4, pp.1059,1069, Dec. 2014. doi: 10.1109/JESTPE.2014.2331958.

[17] Norniella, J.G.; Cano, J.M.; Orcajo, G.A.; Rojas, C.H.; Pedrayes, J.F.; Cabanas, M.F; Melero, M.G., Coupling Inductor Fault Detection and Estimation in Three-Phase Adjustable-Speed Drives With Direct Power Control-Based Active Front-End Rectifiers, Industrial Electronics, IEEE Transactions on , vol.62, no.3, pp.1955,1963, March 2015. doi: 10.1109/TIE.2014.2334651

[18] Nourollah, S.; Pirayesh, A., Restoration of frequency response in inverter-based micro-grids using a novel controlstrategy, Electrical Engineering (ICEE), 2015 23rd Iranian Conference on , vol., no., pp.1452,1456, 10-14 May 2015. doi: 10.1109/IranianCEE.2015.7146449.

[19] Kim, G.H.; Hwang, C.; Jeon, J.H.; Byeon, G.S.; Ahn, J.B.; Jo, C.H., Characteristic analysis of three-phase four-leg inverter based load unbalance compensator for stand-alone microgrid, Power Electronics and ECCE Asia (ICPE-ECCE Asia), 2015 9th International Conference on , vol., no., pp.1491,1496, 1-5 June 2015. doi: 10.1109/ICPE.2015.7167976.

[20] Garcia-Torres, F.; Bordons, C.; Vazquez, S., Voltage predictive control for microgrids in islanded mode based on Fourier transform, Industrial Technology (ICIT), 2015 IEEE International Conference on , vol., no., pp.2358,2363, 17-19 March 2015. doi: 10.1109/ICIT.2015.7125446. 
[21] Vechiu, I.; Etxeberria, A.; Camblong, H.; Vinassa, J.-M., Three-level Neutral Point Clamped Inverter Interface for flow battery/supercapacitor Energy Storage System used for microgrids, Innovative Smart Grid Technologies (ISGT Europe), 2011 2nd IEEE PES International Conference and Exhibition on , vol., no., pp.1,6, 5-7 Dec. 2011 doi: 10.1109/ISGTEurope.2011.6162707.

[22] Rojas-Lobos, F.; Kennel, R.; Cardenas-Dobson, R., 3D-SVM algorithm and capacitor voltage balancing in a 4-leg NPC converter operating under unbalanced and non-linear loads, Power Electronics and Applications (EPE), 2013 15th European Conference on , vol., no., pp.1,10, 2-6 Sept. 2013. doi: 10.1109/EPE.2013.6634684.

[23] Acuna, P.; Moran, L.; Rivera, M.; Aguilera, R.; Burgos, R.; Agelidis, V.G., A Single-Objective Predictive Control Method for a Multivariable Single-Phase Three-Level NPC Converter-Based Active Power Filter, Industrial Electronics, IEEE Transactions on , vol.62, no.7, pp.4598,4607, July 2015. doi: 10.1109/TIE.2015.2393556.

[24] Wang, L.; Zhang, D.; Wang, Y.; Wu, B.; Athab, H., Power and Voltage Balance Control of a Novel Three-phase Solid State Transformer Using Multilevel Cascaded H-Bridge Inverters for Microgrid Applications, Power Electronics, IEEE Transactions on , vol.PP, no.99, pp.1,1. doi: 10.1109/TPEL.2015.2450756.

[25] Wang, Zhaohui; Zhang, Junming; Sheng, Kuang, Modular multilevel power electronic transformer, Power Electronics and ECCE Asia (ICPEECCE Asia), 2015 9th International Conference on , vol., no., pp.315,321, 1-5 June 2015. doi: 10.1109/ICPE.2015.7167803.

[26] Biao Zhao; Qiang Song; Wenhua Liu, A Practical Solution of High-Frequency-Link Bidirectional Solid-State Transformer Based on Advanced Components in Hybrid Microgrid, Industrial Electronics, IEEE Transactions on , vol.62, no.7, pp.4587,4597, July 2015. doi: 10.1109/TIE.2014.2350459.

[27] Nakanishi, T.; Orikawa, K.; Itoh, J.-I., Modular Multilevel Converter for wind power generation system connected to micro-grid, Renewable Energy Research and Application (ICRERA), 2014 International Conference on , vol., no., pp.653,658, 19-22 Oct. 2014. doi: 10.1109/ICRERA.2014.7016466.

[28] Xiong Liu; Poh Chiang Loh; Blaabjerg, F.; Peng Wang, Load sharing using droop control for parallel operation of matrix converters as distributed generator interfaces in isolated mode, Energy Conversion Congress and Exposition (ECCE), 2012 IEEE , vol., no., pp.962,968, 15-20 Sept. 2012. doi: 10.1109/ECCE.2012.6342715.

[29] Planas, E.; Ibarra, E.; Ormaetxea, E.; Andreu, J.; Gabiola, I., Implementation of an electrical micro-grid through matrix converters connected in parallel, Power Electronics and Motion Control Conference (EPE/PEMC), 2010 14th International , vol., no., pp.T3-137,T3-142, 6-8 Sept. 2010. doi: 10.1109/EPEPEMC.2010.5606633.

[30] Empringham, L.; Kolar, J.W.; Rodriguez, J.; Wheeler, P.W.; Clare, J.C., Technological Issues and Industrial Application of Matrix Converters: A Review, Industrial Electronics, IEEE Transactions on , vol.60, no.10, pp.4260,4271, Oct. 2013. doi: 10.1109/TIE.2012.2216231.

[31] Yu Guo; Yougui Guo; Wenlang Deng; Jianlin Zhu; Blaabjerg, F., An improved 4-step commutation method application for matrix converter, Electrical Machines and Systems (ICEMS), 2014 17th International Conference on , vol., no., pp.3590,3593, 22-25 Oct. 2014. doi: 10.1109/ICEMS.2014.7014112.

[32] Jiacheng Wang; Bin Wu; Zargari, N.R., High-power multi-modular matrix converters with sinusoidal input/output waveforms, Industrial Electronics, 2009. IECON '09. 35th Annual Conference of IEEE , vol., no., pp.542,547, 3-5 Nov. 2009. doi: 10.1109/IECON.2009.5414979.

[33] Jiacheng Wang; Bin Wu; Dewei Xu; Zargari, N.R., Indirect SpaceVector-Based Modulation Techniques for High-Power Multimodular Matrix Converters, Industrial Electronics, IEEE Transactions on , vol.60, no.8, pp.3060,3071, Aug. 2013. doi: 10.1109/TIE.2012.2200215.

[34] Mondal, S.; Kastha, D., Improved Direct Torque and Reactive Power Control of a Matrix Converter Fed Grid Connected Doubly Fed Induction Generator, Industrial Electronics, IEEE Transactions on , vol.PP, no.99, pp.1,1. doi: 10.1109/TIE.2015.2459056.

[35] Formentini, A.; Trentin, A.; Marchesoni, M.; Zanchetta, P.; Wheeler, P. Speed Finite Control Set Model Predictive Control of a PMSM Fed by Matrix Converter, Industrial Electronics, IEEE Transactions on , vol.PP, no.99, pp.1,1. doi: 10.1109/TIE.2015.2442526.

[36] Rivera, M.; Rojas, C.; Wilson, A.; Rodriguez, J.; Espinoza, J.; Baier, C.; Muoz, J., Review of predictive control methods to improve the input current of an indirect matrix converter, Power Electronics, IET , vol.7, no.4, pp.886,894, April 2014. doi: 10.1049/iet-pel.2013.0327.

[37] Elizondo, J.L.; Olloqui, A.; Rivera, M.; Macias, M.E.; Probst, O.; Micheloud, O.M.; Rodriguez, J., Model-Based Predictive Rotor Current Control for Grid Synchronization of a DFIG Driven by an
Indirect Matrix Converter, Emerging and Selected Topics in Power Electronics, IEEE Journal of , vol.2, no.4, pp.715,726, Dec. 2014. doi: 10.1109/JESTPE.2014.2349952.

[38] Rodriguez, J.; Rivera, M.; Kolar, J.W.; Wheeler, P.W., A Review of Control and Modulation Methods for Matrix Converters, Industria Electronics, IEEE Transactions on, vol.59, no.1, pp.58,70, Jan. 2012. doi: 10.1109/TIE.2011.2165310

[39] Gruson, F.; Le Moigne, P.; Delarue, P.; Videt, A.; Cimetiere, X.; Arpilliere, M., A Simple Carrier-Based Modulation for the SVM of the Matrix Converter, Industrial Informatics, IEEE Transactions on , vol.9, no.2, pp.947,956, May 2013. doi: 10.1109/TII.2012.2224354

[40] Dabour, S.M.; Allam, S.M.; Rashad, E.M., A simple CB-PWM technique for five-phase matrix converters including over-modulation mode, GCC Conference and Exhibition (GCCCE), 2015 IEEE 8th , vol., no., pp.1,6, 1-4 Feb. 2015. doi: 10.1109/IEEEGCC.2015.7060058.

[41] Keping You; Dan Xiao; Rahman, M.F.; Uddin, M.N., Applying Reduced General Direct Space Vector Modulation Approach of ACAC Matrix Converter Theory to Achieve Direct Power Factor Controlled Three-Phase ACDC Matrix Rectifier, Industry Applications, IEEE Transactions on , vol.50, no.3, pp.2243,2257, May-June 2014. doi: 10.1109/TIA.2013.2285956

[42] Inoue, K.; Shioda, M.; Katade, M.; Goto, A.; Morishita, S.; Itoh, J.; Koiwa, K., Space vector modulation based on virtual indirect control for high frequency AC-linked matrix converter, Power Electronics Conference (IPEC-Hiroshima 2014 - ECCE-ASIA), 2014 International , vol. no., pp.130,137, 18-21 May 2014. doi: 10.1109/IPEC.2014.6869570.

[43] Sebtahmadi, S.S.; Pirasteh, H.; Kaboli, S.H.A.; Radan, A.; Mekhilef, S., A 12-Sector Space Vector Switching Scheme for Performance Improvement of Matrix-Converter-Based DTC of IM Drive, Power Electronics, IEEE Transactions on , vol.30, no.7, pp.3804,3817, July 2015. doi: 10.1109/TPEL.2014.2347457.

[44] Khodamoradi, A.; Kargar, H.K.; Nateghi, A., Fuzzy logic control of matrix-converter-based WECS in order to performance improvement, Electrical Engineering (ICEE), 2014 22nd Iranian Conference on , vol., no., pp.713,718, 20-22 May 2014. doi: 10.1109/IranianCEE.2014.6999631.

[45] Venugopal, C., ANFIS based Field Oriented Control for Matrix Converter fed Induction Motor, Power and Energy (PECon), 2010 IEEE International Conference on , vol., no., pp.74,78, Nov. 29 2010-Dec. 1 2010. doi: 10.1109/PECON.2010.5697560.

[46] Niassati, N.; Bagher, M.; Sadati, A.M.; Hajihosseinlu, A.; Afjei, E., Improvement of output voltage and input current for a matrix converter using genetic algorithm, Cyber Technology in Automation, Control, and Intelligent Systems (CYBER), 2012 IEEE International Conference on , vol., no., pp.238,242, 27-31 May 2012. doi: 10.1109/CYBER.2012.6392560.

[47] Lopez, M.; Rodriguez, J.; Silva, C.; Rivera, M., Predictive Torque Control of a Multidrive System Fed by a Dual Indirect Matrix Converter, Industrial Electronics, IEEE Transactions on , vol.62, no.5, pp.2731,2741, May 2015. doi: 10.1109/TIE.2014.2364986.

[48] Xiong Liu; Peng Wang; Poh Chiang Loh; Blaabjerg, F., A Three-Phase Dual-Input Matrix Converter for Grid Integration of Two AC Type Energy Resources, Industrial Electronics, IEEE Transactions on , vol.60, no.1, pp.20,30, Jan. 2013. doi: 10.1109/TIE.2012.2183838.

[49] Chithirai Selvan, K.; Arunsaiikar, G., Grid integration of hybrid renewable energy system using versatile matrix converter, Emerging Trends In New and Renewable Energy Sources And Energy Management (NCET NRES EM), 2014 IEEE National Conference On , vol., no., pp.153,158, 16-17 Dec. 2014. doi: 10.1109/NCETNRESEM.2014.7088758.

[50] Kandasamy, V.; Manoj, R., Grid integration of AC and DC energy resources using multi-input nine switch matrix converter, Green Computing Communication and Electrical Engineering (ICGCCEE), 2014 International Conference on , vol., no., pp.1,4, 6-8 March 2014. doi: 10.1109/ICGCCEE.2014.6922378.

[51] Xu Lie; Clare, J.C.; Wheeler, P.W.; Empringham, L.; Li Yongdong, Capacitor Clamped Multilevel Matrix Converter Space Vector Modulation, Industrial Electronics, IEEE Transactions on , vol.59, no.1, pp.105,115, Jan. 2012. doi: 10.1109/TIE.2011.2146218.

[52] Diaz, M.; Cardenas, R.; Mauricio Espinoza, B.; Mora, A.; Rojas, F., A novel LVRT control strategy for Modular Multilevel Matrix Converter based high-power Wind Energy Conversion Systems, Ecological Vehicles and Renewable Energies (EVER), 2015 Tenth International Conference on , vol., no., pp.1,11, March 31 2015-April 22015. doi: 10.1109/EVER.2015.7113026.

[53] Huang, Lang; Yang, Xu; Zhang, Bin; Qiao, Liang; Li, Hongchang; Tian, Mofan, Hierarchical model predictive control of modular multilevel matrix converter for low frequency AC transmission, Power Electronics 
and ECCE Asia (ICPE-ECCE Asia), 2015 9th International Conference on , vol., no., pp.927,933, 1-5 June 2015. doi: 10.1109/ICPE.2015.7167892.

[54] Bifaretti, S.; Zanchetta, P.; Watson, A.; Tarisciotti, L.; Clare, J.C., Advanced Power Electronic Conversion and Control System for Universal and Flexible Power Management, Smart Grid, IEEE Transactions on , vol.2, no.2, pp.231,243, June 2011. doi: 10.1109/TSG.2011.2115260.

[55] Valencia, F.; Saez, D.; Collado, J.; Avila, F.; Marquez, A.; Espinosa, J.J., Robust Energy Management System Based on Interval Fuzzy Models, Control Systems Technology, IEEE Transactions on , vol.PP, no.99, pp.1,1. doi: 10.1109/TCST.2015.2421334.

[56] Tedesco, F.; Mariam, L.; Basu, M.; Casavola, A.; Conlon, M., Economic Model Predictive Control based Strategies for Cost-effective Supervision of Community Microgrids Considering Battery Lifetime, Emerging and Selected Topics in Power Electronics, IEEE Journal of , vol.PP, no.99, pp.1,1. doi: 10.1109/JESTPE.2015.2446894.

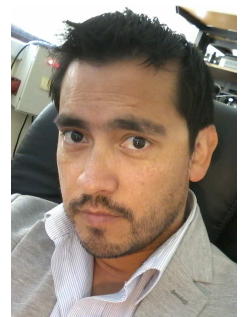

Marco Rivera (S'09-M'11) was born in Talca, Chile, in 1982. He received the B.Sc. degree in electronics engineering and the M.Sc. degree in electrical engineering from the Universidad de Concepcin, Concepcin, Chile, in 2007 and 2008, respectively, and the Ph.D. degree from the Department of Electronics Engineering, Universidad Tcnica Federico Santa Mara, Valparaso, Chile, in 2011. Since 2013 is with the Energy Conversion and Power Electronics Research Group at the Universidad de Talca. He is currently an Associate Professor with the Department of Electrical Engineering at the Universidad de Talca, Curicó, Chile. His main research areas are digital control applied to power electronics, matrix converters, predictive control and control of power converters for renewable energy applications. Prof. Rivera was recipient of the Best $\mathrm{PhD}$ Thesis Award 2012, award given by the Chilean Academy of Science for $\mathrm{PhD}$ thesis developed in 2011 by national and foreign students in any Exact or Nature Sciences Program in Chile. In August 2015, Prof. Rivera was awarded with the Outstanding Engineer 2015 Award of the Electrical-Electronics Industry Association and the IEEE-Chile Section and also he received the Second Prize Paper Award in the 2015 IEEE Journal of Emerging and Selected Topics in Power Electronics.

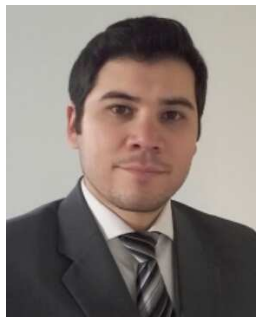

Sergio Toledo (S'09-M'12) was born in Luque, Paraguay in 1985. He received the Electronic Engineer degree from Universidad Nacional de Asuncin, Paraguay in 2011 and the M.Sc. degree from Centro de Investigacin Cientfica y Educacin Superior de Ensenada, Mxico, in 2014. Since 2010 he is professor in the Engineering Faculty of Universidad Nacional de Asuncin. His research interests include non linear control systems, new converter topologies and control of power converters. He is currently a Phd student in the Department of Electrical Engineering at the Universidad de Talca, Curicó, Chile.

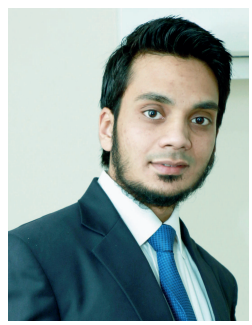

Usman Nasir is currently associated with Power Electronics and Machine Control (PEMC) group at The University of Nottingham, UK as a $\mathrm{PhD}$ student. He is a recipient of Dean of Engineering Scholarship For International Research Excellence for his $\mathrm{PhD}$ studies. He received B.Sc. degree in electrical engineering from the National University of Sciences and Technology (NUST), Pakistan and M.Sc. degree from North China Electric Power University, Beijing, China in 2013 and 2015, respectively. His research interests include new matrix converter based topologies, novel commutation algorithms, new modulation techniques and also Model Predictive Control (MPC) for power electronic converters.

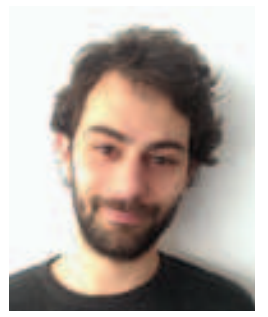

Alessandro Costabeber (S09M13) received the Degree with honours in Electronic Engineering from the University of Padova, Padova, Italy, in 2008 and the Ph.D. in Information Engineering from the same university in 2012, on energy efficient architectures and control techniques for the development of future residential microgrids. In the same year he started a two-year research fellowship with the same university. In 2014 he joined the PEMC group, Department of Electrical and Electronic Engineering, University of Nottingham, Nottingham, UK as Lecturer in Power Electronics. His current research interests include HVDC converters topologies, high power density converters for aerospace applications, control solutions and stability analysis of AC and DC microgrids, control and modelling of power converters, power electronics and control for distributed and renewable energy sources. Dr. Costabeber received the IEEE Joseph John Suozzi INTELEC Fellowship Award in Power Electronics in 2011.

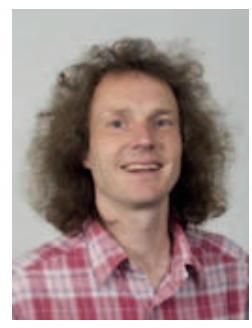

Pat Wheeler received his BEng [Hons] degree in 1990 from the University of Bristol, UK. He received his $\mathrm{PhD}$ degree in Electrical Engineering for his work on Matrix Converters from the University of Bristol, UK in 1994. In 1993 he moved to the University of Nottingham and worked as a research assistant in the Department of Electrical and Electronic Engineering. In 1996 he became a Lecturer in the Power Electronics, Machines and Control Group at the University of Nottingham, UK. Since January 2008 he has been a Full Professor in the same research group. He is currently Head of the Department of Electrical and Electronic Engineering at the University of Nottingham. He is an IEEE PELs Member at Large and an IEEE PELs Distinguished Lecturer. He has published 400 academic publications in leading international conferences and journals. 